Braz J Med Biol Res, January 2011, Volume 44(1) 62-65

doi: 10.1590/S0100-879X2010007500134

\section{Anti-Leishmania titers and positive skin tests in patients cured of kala-azar}

G.M.C. Viana, M.D.S.B. Nascimento, J.A. Diniz Neto, E.M.F. Rabelo, J.R. Binda Júnior, O.M. Santos Júnior, A.C. Santos, C.S. Galvão and R.S. Guimarães

The Brazilian Journal of Medical and Biological Research is partially financed by
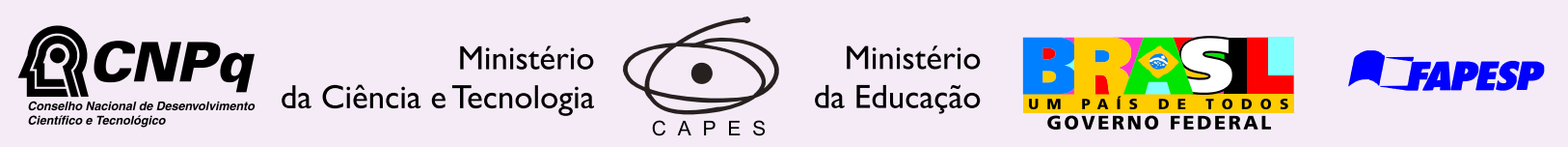

Institutional Sponsors
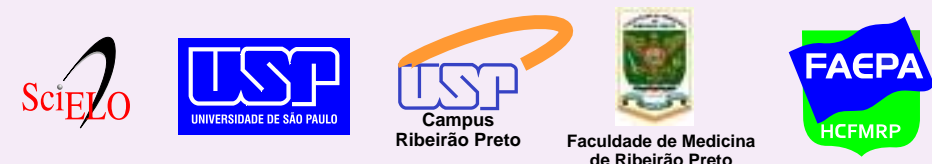

Hotsite of proteomics metabolomics developped by:

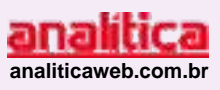

Thermo
SCIEN TIFIC 


\title{
Anti-Leishmania titers and positive skin tests in patients cured of kala-azar
}

\author{
G.M.C. Viana ${ }^{1,2}$, M.D.S.B. Nascimento ${ }^{1}$, J.A. Diniz Neto ${ }^{1}$, \\ E.M.F. Rabelo ${ }^{1}$, J.R. Binda Júnior ${ }^{2}$, O.M. Santos Júnior ${ }^{1}$, A.C. Santos ${ }^{1}$, \\ C.S. Galvão ${ }^{1}$ and R.S. Guimarães ${ }^{1}$ \\ ${ }^{1}$ Departamento de Patologia, Universidade Federal do Maranhão, São Luís, MA, Brasil \\ 2Departamento de Pós-Graduação, Centro Universitário do Maranhão (UNICEUMA), São Luís, MA, Brasil
}

\begin{abstract}
Visceral leishmaniasis (VL), also known as kala-azar, is an important public health problem. If not treated, virtually all clinically symptomatic patients die within months. The diagnosis is based on the Montenegro skin test (MST) and anti-Leishmania titers. Nevertheless, the time required for cured individuals living in a leishmaniasis-endemic area to present a positive skin test and negative anti-Leishmania serology is known. To determine the cellular and humoral immune response profile in relation to different times post-VL cure, a cross-sectional study was conducted on subjects from a kala-azar endemic area in Paço do Lumiar, MA, Brazil, on the basis of 1995-2005 notifications reported by the National Health Foundation/Regional Coordination of Maranhão. We visited cured individuals with a history of VL within the last 10 years. Seventy-four subjects (30 females) ranging in age from 1 to 44 years were included, all of them symptom free at the time of the study. A cellular immune response was observed in 73 $(98.6 \%)$ subjects, whereas no significant antibody titers were detected by indirect immunofluorescence (IIF) in the sera of 69 $(93.2 \%)$ cases. Ten years post-cure, 39 (52\%) subjects had a positive MST and negative IIF reaction, while in one subject the skin and anti-Leishmania serology tests were negative. Two other subjects were positive in both tests 1 year after cure. These data suggest that a cellular immune response may still be present in subjects cured of VL regardless of post-cure time, and that the parasite persists in the host after clinical cure of the disease. This would explain the persistence of significant Leishmania sp antibody titers in some subjects after treatment.
\end{abstract}

Key words: Human visceral leishmaniasis; Montenegro's intradermal reaction; Indirect immunofluorescence

\section{Introduction}

Visceral leishmaniasis (VL), also known as kala-azar, is an important public health problem that affects poor populations in 70 countries in Asia, East Africa, South America, and the Mediterranean region. More than $90 \%$ of new cases occur in the 6 most affected countries, namely Bangladesh, Brazil, India, Ethiopia, Kenya, and Sudan (1). The number of patients with VL has increased over the past decade, affecting mainly children younger than 10 years and HIV-infected patients. Leishmaniasis has emerged as an opportunistic infection, representing an important co-infection in immunodepressed patients and a major sanitary problem (2).

If not treated, virtually all clinically symptomatic patients die within months. Diagnosis of VL is based on epidemiological data and clinical and laboratory findings, but the definitive diagnosis can only be made by detecting the parasite in infected tissues (3).

Various immunological abnormalities have been documented in VL patients, including unresponsive skin tests (Montenegro skin test, MST) and high Leishmania antibody titers, which have been used as a laboratory diagnostic criterion of the disease $(4,5)$. Immunocompetent individuals show negative results in skin tests when they are in the acute phase of VL. Serological tests may be particularly useful for the diagnosis of visceral leishmaniasis, as they have a high predictive value in the diagnosis of immunocompetent individuals.

Despite the laboratory findings, the time required for cured individuals living in a leishmaniasis endemic area to show a positive reaction of cellular hypersensitivity (MST) and negative serology (anti-Leishmania) is not known. In the present study, we determined the cellular and humoral

Correspondence: G.M.C. Viana, Rua Nova, Quadra H, Casa 2, Sítio Leal, 65041-140 São Luís, MA, Brasil.

E-mail: gracaviana@globo.com

Received June 6, 2010. Accepted October 29, 2010. Available online November 26, 2010. Published January 17, 2011. 
immune response profile in relation to different post-cure times of VL, and discussed future perspectives that may contribute to intervention and control of this protozoosis.

\section{Material and Methods}

Across-sectional study was conducted on subjects from a kala-azar endemic area (Vila São José, a municipality of Paço do Lumiar, Island of São Luís do Maranhão, Brazil). We visited every house that had individuals with a history of VL over a range of up to 10 years (fever, anemia, and splenomegaly), a positive indirect immunofluorescence (IIF) reaction (titer $\geq 1: 80$ ) test, and demonstration of amastigote forms of Leishmania in bone marrow aspirates (myelogram). The addresses were obtained from the notifications between 1995 and 2005 reported by the National Health Foundation/ Regional Coordination of Maranhão (FUNASA/COREMA). All individuals had been treated with $\mathrm{N}$-methylglucamine antimoniate at a dose of $20 \mathrm{mg} \mathrm{Sb}{ }^{5+} \cdot \mathrm{kg}^{-1} \cdot \mathrm{day}^{-1}$ for 20 days at the time of the disease. These individuals were submitted to clinical and immunological evaluation in 2005 , corresponding to an interval of 1 to 10 years of treatment. The subjects showed no signs or symptoms suggestive of the disease at the time of the present study. The study was approved by the Ethics Committee of the Universidade Federal do Maranhão, and written informed consent was obtained from all subjects.

IIF testing was performed for the evaluation of the humoral immune response, and the MST was used to determine the cellular immune response.

For the MST, antigen from Leishmania (L.) amazonensis promastigotes $\left(5 \times 10^{7}\right.$ parasites $\left./ \mathrm{mL}\right)$, produced at BioManguinhos/FIOCRUZ (Ministry of Health, Rio de Janeiro, Brazil), was used at a standard concentration of $40 \mu \mathrm{g} /$ $\mathrm{mL}$ protein nitrogen diluted $1: 10,000$ in saline merthio- late. Antigen $(0.1 \mathrm{~mL})$ was injected intradermally in the anterior side of the left forearm with a tuberculin syringe and readings were taken 48 to $72 \mathrm{~h}$ after injection. The size of the papule was delimited with a ball-point pen and measured with a millimeter ruler. The reaction was considered to be positive when both the cross-sectional and longitudinal diameter of the induration was $\geq 5 \mathrm{~mm}$. The same researcher applied the antigen and read the result.

The IIF test was performed as previously described (6). For the test, a 5-mL blood sample was collected from each individual and processed at the state Laboratory of Endemic Diseases. Antibody titers $\geq 1: 80$ were taken to be positive. Descriptive presentation of the data consisted of the tabulation of frequency and proportions using the EpiInfo software, version 6.

\section{Results}

Forty-four of the 74 subjects with a history of VL were males and 30 were females, with no significant difference in terms of gender. Age ranged from 1 to 44 years.

All subjects were symptom free at the time of this study. None of the subjects presented hepato- or splenomegaly upon physical examination or any other anomaly. The time after cure of the disease and the frequency of a positive MST and IIF reaction are shown in Table 1. Ten years post-cure, $39(52 \%)$ subjects had a positive MST and negative IIF reaction; only one subject presented negative MST and IIF reactions, whereas three other subjects presented positive serology and a positive cellular response. At 1 year post-cure, two subjects were still serologically positive, but already presented a positive MST. Two to 9 years post-cure, all subjects presented negative serology and a positive cellular response. In summary, over the 1 to 10 years of follow-up, $69(93.2 \%)$ subjects presented

Table 1. Response to the Montenegro skin test and indirect immunofluorescence test serology of subjects up to 10 years after cure of visceral leishmaniasis (Vila São José, MA, Brazil).

\begin{tabular}{lccc}
\hline $\begin{array}{l}\text { Time (years) elapsed between the } \\
\text { disease and current assessment }\end{array}$ & $\begin{array}{c}\text { Number of } \\
\text { subjects }\end{array}$ & $\begin{array}{c}\text { Montenegro } \\
\text { skin test }\end{array}$ & $\begin{array}{c}\text { Anti-Leishmania antibodies } \\
\text { (indirect immunofluorescence test) }\end{array}$ \\
\hline 10 & 39 & $(+)$ & $(-)$ \\
10 & 3 & $(+)$ & $(+)$ \\
10 & 1 & $(-)$ & $(-)$ \\
9 & 8 & $(+)$ & $(-)$ \\
8 & 1 & $(+)$ & $(-)$ \\
7 & 1 & $(+)$ & $(-)$ \\
6 & 5 & $(+)$ & $(-)$ \\
5 & 10 & $(+)$ & $(-)$ \\
4 & 2 & $(+)$ & $(-)$ \\
3 & 1 & $(+)$ & $(-)$ \\
2 & 1 & $(+)$ & $(-)$ \\
1 & 2 & $(+)$ & $(+)$ \\
\hline
\end{tabular}


negative serology and $73(98.6 \%)$ showed a positive response to the Leishmania skin test.

\section{Discussion}

In the present study, we found that $98.6 \%$ of the subjects were MST positive 10 years post-cure, which contrasts with findings obtained in the endemic area of Jacobina, BA, where only $15.5 \%$ of the individuals presented a cellular response at 4 to 9 years post-cure of the disease (7), and with Mayrink et al. (8) who reported a $4.1 \%$ positivity rate in individuals with post-cure periods ranging from 8 to 720 days (8). Also, a lower percentage of positive MST was found in another endemic region in Teresina (Piauí State), with $36.9 \%$ positivity in 1105 subjects (9).

Years of post-cure are expected to lead to a positive cellular response (MST positive) and loss of specific antibodies (IIF negative), as was the case with 39 of our subjects $(52 \%)$ after 10 years. A positive MST has been observed after 1 year post-cure.

In areas under strict epidemiological control where prophylactic measures are routinely performed, exposure to the parasitic agent becomes less frequent. As a consequence, individuals become non-responders to the Leishmania skin test, as cellular immunity is antigen dependent and requires constant stimulation for its maintenance (10-13).

The observation of high anti-Leishmania antibody titers even at 10 years post-cure raises the question of re-infection. Alternatively, parasites may persist in the host for long

\section{References}

1. Ministério da Saúde, Secretaria de Vigilância em Saúde, Departamento de Vigilância Epidemiológica. Manual de vigilância e controle da leishmaniose visceral. Brasília: Ministério da Saúde; 2004.

2. Badaro R. Progress of research in visceral leishmaniasis in the endemic area of Jacobina-Bahia 1934-1989. Rev Soc Bras Med Trop 1988; 21: 159-164.

3. World Health Organization. Control of the leishmaniasis. Geneva: WHO, Technical Report Series; No. 793; 1990.

4. Pandey K, Sinha PK, Ravidas VN, Kumar N, Verma N, Lal $\mathrm{CS}$, et al. Nexus of infection with human immunodeficiency virus, pulmonary tuberculosis and visceral leishmaniasis: a case report from Bihar, India. Am J Trop Med Hyg 2005; 72: 30-32.

5. Duarte C, Candeias N, Flora L, Cardoso O, Rodrigues P, Machado J, et al. Visceral leishmaniasis and HIV infection: report of 30 cases. Antivir Ther 2003; 8 (1 Suppl): 30-37.

6. Camargo ME, Rebonato $\mathrm{C}$. Cross-reactivity in fluorescence tests for Trypanosoma and Leishmania antibodies. A simple inhibition procedure to ensure specific results. Am J Trop Med Hyg 1969; 18: 500-505.

7. Badaró R, Carvalho EM, Orge MGO, Teixeira RS, Rocha H. Imunidade humoral e celular em indivíduos curados de Leishmaniose visceral. Rev Soc Bras Med Trop 1985; 18 (2 periods, a fact that would lead to constant stimulation of the immune system. This may explain the high incidence of this protozoosis among immunodepressed patients who have no history of the disease but who live in or visit VL-endemic areas. This demonstrates that Leishmania is an opportunistic protozoan (14) and thus supports the view that antibody titers cannot be used as a criterion of cure of VL (15).

The fact that 1 subject was still MST negative at 10 years post-cure may be explained by an initial phase of re-infection, but with not enough antibodies to produce a positive IIF. Our findings indicate that at 1 year after cure subjects may already present a positive MST test, and that 2 years are needed for negative serology (IIF) to be present.

These data support the need for long-term, preferentially multicenter, immunological studies of kala-azar to permit the follow-up of patients at 3-month intervals in order to determine the time of occurrence of a positive MST and negative serology. Such studies would contribute to a better understanding of the parasite-host relationship, thus permitting better epidemiological intervention, a reduction of morbidity and mortality, and better control of the disease.

\section{Acknowledgments}

We thank CNPq for granting a scientific initiation fellowship.
Suppl): $77-83$

8. Mayrink W, Magalhaes PA, Batista SM, da Costa CA. [Diagnosis of kala-azar. II. Study of Montenegro's test and detection of Leishmania in skin material from patients with kala-azar, before and after antimony treatment]. Rev Inst Med Trop São Paulo 1971; 13: 268-271.

9. Werneck GL, Pereira TJCF, Farias GC, Silva FO, Chaves FC, Gouvêa MV, et al. Avaliação da efetividade das estratégias de controle da leishmaniose visceral na cidade de Teresina, Estado do Piauí, Brasil: Resultados do inquérito inicial 2004. Epidemiol Serv Saúde 2008; 17: 87-96.

10. Nascimento MDSB, Viana GMC, Costa JML. Aspectos epidemiológicos determinantes na manutenção da leishmaniose visceral no Estado do Maranhão-Brasil. Rev Soc Bras Med Trop 1996; 29 (3 Suppl): 233-240.

11. Maache M, Azzouz S, Diaz de la GR, Alvarez P, Gil R, de Pablos LM, et al. Host humoral immune response to Leishmania lipid-binding protein. Parasite Immunol 2005; 27 : 227-234.

12. Saha S, Mondal S, Banerjee A, Ghose J, Bhowmick S, Ali N. Immune responses in kala-azar. Indian J Med Res 2006; 123: 245-266.

13. Kumar P, Pai K, Tripathi K, Pandey HP, Sundar S. Immunoblot analysis of the humoral immune response to Leishmania 
donovani polypeptides in cases of human visceral leishmaniasis: its usefulness in prognosis. Clin Diagn Lab Immunol 2002; 9: 1119-1123.

14. Badaro R, Carvalho EM, Rocha H, Queiroz AC, Jones TC. Leishmania donovani: an opportunistic microbe associated with progressive disease in three immunocompromised patients. Lancet 1986; 1: 647-649.
15. Nascimento MSDB, Souza EC, Silva LM, Leal PC, Cantanhede KL, Bezerra GFB, et al. Prevalência de infecção por Leishmania chagasi utilizando os métodos de ELISA (rK39 e Crude) e Intradermoreação de Montenegro em área endêmica do Maranhão, Brasil. Cad Saúde Pública 2005; 21: 1801-1807. 